\title{
LEANDRO FERNÁNDEZ DE MORATÍN ENJUICIADO, Y ELOGIADO, EN LOS ALBORES DEL ROMANTICISMO: EL JUICIO CRÍTICO DE JOAQUÍN ROCA Y CORNET1
}

\section{LEANDRO FERNÁNDEZ DE MORATÍN: PRAISED AND JUDGED IN THE ROMANTICISM DAWNS: THE CRITICAL JUDGEMENT OF JOAQUÍN ROCA Y CORNET}

\author{
Jesús Cañas Murillo \\ Universidad de Extremadura, España \\ jcanas@unex.es
}

\begin{abstract}
Resumen:
Estudio de los comentarios y elogios que recibió la figura y la obra de Leandro Fernández de Moratín en los últimos años del reinado de Fernando VII, previos a la aparición del Romanticismo en España. La investigación se centra en la aportación que hizo, en este campo, el estudioso y literato barcelonés Joaquín Roca y Cornet, en su Juicio crítico de don Leandro Fernández de Moratín, como autor cómico. Se recogen los datos biográficos y bibliográficos que se han podido localizar sobre Joaquín Roca, se examina el contenido de su obra y el contexto en el que se redactó, y se justifica el modo en el que fue efectuada su versión definitiva.
\end{abstract}

Palabras clave: Siglo XVIII español. Ilustración. Historiografía y crítica literarias. Teatro. Leandro Fernández de Moratín. Joaquín Roca y Cornet.

\begin{abstract}
:
Study of the commentaries and praises that the figure and the production of Leandro Fernández de Moratin received in the last years of the of the Fernando VII'sreign, before the appearance of Spanish Romanticism. The investigation focuses on the contribution made, in this field, by the Barcelonian scholar and writer Joaquin Roca y Cornet, in his Juicio crítico de don Leandro Fernández de Moratín, como autor cómico. The biographical and bibliographic data that could be located about Joaquin Roca are collected, the contents of his work and the context in which it was written are examined, and the way in which his definitive version was made is justified.
\end{abstract}

Keywords: Spanish 18th Century. Enlightenment. Literary Historiography and Criticism. Theater. Leandro Fernández de Moratín. Joaquín Roca y Cornet.

Recibido: 17 de marzo de 2018

Aprobado: 30 de mayo de 2018

\footnotetext{
${ }^{1}$ Esta investigación ha sido realizada dentro del proyecto de investigación Teoría de la lectura y hermenéutica literaria en la Ilustración (1750-1808): edición y estudio de fuentes documentales y literarias, FFI2016-80168$\mathrm{P}$, concedido por el Ministerio español de Economía y Competitividad, dentro del Plan Nacional I+D.
} 


\section{MORATÍN Y SU TEATRO EN LOS INICIOS DEL OCHOCIENTOS}

El reconocimiento público que recibió la obra dramática de Leandro Fernández de Moratín, casi desde el mismo momento de producirse su difusión por los años en que fue compuesta, es un hecho histórico que, en muchas ocasiones, ha sido resaltado por críticos e historiadores de la literatura española de la Ilustración. De sus creaciones se hicieron pronto, ya desde finales del siglo XVIII y principios del XIX, análisis y valoraciones, generalmente positivas. Recordemos, por citar algunos ejemplos, los elogios que vieron la luz en periódicos de la época, como Correo de Madrid, Memorial Literario, Diario de Barcelona, El Clamor Público, o Semanario Pintoresco Español. También, trabajos de carácter más erudito, crítico y académico, como los debidos a Pietro Napoli Signorelli, Juan Sempere y Guarinos, Juan de Dios Gil de Lara, José de la Revilla, Antonio Alcalá Galiano, o Manuel Silvela. ${ }^{2}$

En la presente investigación nos vamos a ocupar de uno de los textos que fueron dedicadosa Leandro Fernández de Moratín y su producción en épocas próximas a la fecha en la que se produjo su fallecimiento, acaecido, como es sabido, en el exilio, en París, el 21 de julio de 1828. Se trata de la obra que sobre él compuso Joaquín Roca y Cornet, quien la tituló Juicio crítico de don Leandro Fernández de Moratín, como autor cómico, y la publicó en Barcelona, en la Imprenta y Librería de A. y F. Oliva, en 1833, con el seudónimo de Inarco Cortejano, claro homenaje al autor de El sí de las niñas, que utilizó, habitualmente, en sus obras, -junto a otros como Melitón Fernández y Efrén Lardnaz y Morante-, el seudónimo de Inarco Celenio, con el que era conocido en la Academia italiana de Los Arcades de Roma.

\section{EL JUICIO CRÍTICO, SU CREADOR Y SU OBRA}

El Juicio crítico de don Leandro Fernández de Moratín, como autor cómico, aparece firmado con el seudónimo de Inarco Cortejano, como acabamos de indicar. Tras este sobrenombre se oculta el nombre de su verdadero autor, que no es otro que el autor catalán Joaquín Roca y Cornet, natural de Barcelona, ciudad en la nacióel día 6 de febrero de 1804, y en la que vivió hasta que se produjo, allí mismo, el 11 de enero de 1873, su fallecimiento, cuando todavía no había cumplido sesenta y nueve años de edad (Elías de Molins, 1895; Gil Novales, 2018; Rodríguez Sánchez, 1994; Torres Amat, 1836).

Roca y Cornet pasó la Guerra de la Independencia en Mallorca, lugar al que se trasladaron sus padres durante la contienda. Estudió, a su regreso a Barcelona en 1814, entre

\footnotetext{
2 Véanse títulos y datos bibliográficos en la «Bibliografía» sita al final de nuestro artículo.
} 
otras materias, Taquigrafía, Matemáticas, Física Experimental, Gramática Española y Latina, Humanidades, Filosofía Escolástica, Economía Política, y, sobre todo, en la Universidad de Cervera, Derecho Natural, Principios de Legislación Universal, Derecho Romano, Derecho Canónico, Derecho Español y Derecho Público.Era gran aficionado a las letras y a ellas dedicó buena parte de su actividad profesional, obteniendo buen reconocimiento en su época. Suele ser citado como uno de los más ilustres representantes de la identificada como Escuela Apologética Catalana. Casó, en 1833, en su ciudad natal, con Josefa Fiter y de Roca.

Trabajó en la prensa periódica. Lo propusieron como Director de la Gaceta de Madrid en 1832, cargo que rechazó al no desear trasladar su domicilio a la capital de España. A los quince años ya había publicado su primer trabajo en el Diario de Barcelona, periódico con el que colaboró con asiduidad, entre 1828 y 1830, hasta que fue nombrado redactor único en mazo de 1830, puesto en el que se mantuvo hasta septiembre de 1839, llegando allí a publicar doscientas cuarenta colaboraciones, entre poemas y artículos. La colaboración con el Diario de Barcelona no se detuvo en ese año. Entre 1850 y 1854 se encargó en él de la sección de temas religiosos. Utilizó en el Diario diferentes seudónimos para firmar sus aportaciones, como el ya mencionado de Inarco Cortejano, Lampillo, Cintio... Colaboró también con el Boletín Oficial de Cataluña. Fundó la revista La Religión, de la que fue su redactor único y su Director (cesó en 1841), y de la que se dieron a la luz nueve tomos. Fundó, junto a su amigo Jaime Balmes, y con José Ferrer y Subirana, La Civilización (18411843), de periodicidad quincenal. Colaboró, también, en La España Católica, entre 1856 y 1857; en Guía del Magisterio, en 1858; El Monitor de Primera Enseñanza, entre 1860 y 1866; en La Notaría; en El Iris; en La Luz, semanario fundado, en 1861, por José Amores; en La Esperanza, periódico carlista de Madrid del que llegó a ser Director.

Ocupó diversos cargos públicos. Fue, desde agosto de 1834, Censor Regio de la Provincia de Barcelona, puesto al que renunció en febrero de 1835. En 1837 fue designado como Censor del Teatro por el Gobernador Civil de Barcelona. En 1843 es elegido por el Ayuntamiento de Barcelona como miembro de la Comisión Local de Instrucción Primaria, cargo que ocupó durante seis años. En 1844 recibió el nombramiento, por parte del Ayuntamiento de Barcelona, de Bibliotecario Primero, -equivalente a encargado y jefe-, de la Biblioteca Municipal de su ciudad, conocida después como Biblioteca Pública de Barcelona. Formó parte, en cuatro ocasiones, en 1846 y 1847, del tribunal de oposiciones a Cátedras de Religión y Moral, de Historia, de Psicología, Ideología y Lógica, y de Retórica y Poética, 
convocadas para plazas del Instituto agregado a la Universidad de Barcelona. En 1849 recibió nombramiento regio de Bibliotecario Primero de la Universidad y Provincia de Barcelona, así como, el nueve de octubre de ese mismo año, de Secretario de la Dirección y Junta Superior Consultiva de Archivos del Distrito de la Audiencia Territorial de Barcelona. En 1852 ocupa el cargo de Censor de las inscripciones y epitafios del Cementerio General de su localidad. En 1857 es elegido, por el Colegio de Notarios de Barcelona, para ocupar una plaza en su Junta Permanente de Gobierno, y se le encarga la defensa de intereses y privilegios de dicha institución. En 1860 recibe nombramiento regio de Vocal en la Junta de Instrucción Primaria de la Provincia de Barcelona; y, tras constituirse el cuerpo de Archiveros, Bibliotecarios y Anticuarios, Ayudante Cuarto, con honores de Bibliotecario Primero, destinado en las Bibliotecas Provincial y Universitaria de Barcelona, cargo en el que desempeñó una buena labor, por lo que, en 1861, fue nombrado Ayudante de Primer Grado, y, en 1862, Oficial Tercero, y, en 1867, Oficial Segundo.

Fue, desde 1836, Académico numerario de la Real Academia de Buenas Letras de Barcelona, en la que llegó a ser Vicepresidente, desde el 9 de julio de 1860, en la que mantuvo una activa participación, y en la que presentó diversas memorias, como,por ejemplo, el 25 de octubre de 1838, una memoria en la que abordaba el tema de las relaciones, enlaces y contactos entre las ciencias y las letras, y otra, más tardía, el 4 de marzo de 1849, dedicada a su amigo Jaime Balmes, como historiador y como literato, que tituló Balmes considerado en sus estudios, como historiador, como literato y como poeta. También perteneció a la Sociedad Filodramática de Barcelona, desde 1836; a la Sociedad Arqueológica Tarraconense, desde 1845, como Corresponsal; y al Centro Literario, desde 1855, como Socio de Mérito. Recibió el nombramiento, en 1860, de Mantenedor del Consistorio de los Juegos Florales de Barcelona.

Entre las publicaciones de Joaquín Roca y Cornet se cuentan poemas y textos en verso, como la parte en verso del Compendio de la Historia de España de José Pinos (1841);obras teatrales, como La última noche de Babilonia (1848), drama bíblico que sirvió de texto para un oratorio de Bernat Calvó Puig y Capdevila; y, sobre todo, artículos y ensayos, muchos de ellos de tema religioso, y de apología de la religión católica más tradicional, si bien también otros abordan asuntos históricos y de crítica e historia literarias. Entre todos se hallan, además de los citados, y del mencionado Juicio crítico de Don Leandro Fernández de Moratín, como autor cómico (1833), obras como Importancia moral, literaria y 
económica de una colección escogida de los autores más célebres de la docta antigüedad traducidos en nuestro idioma (1840), Sobre la pena capital origen del derecho de castigar (1841), Conversión de un israelita (1842), Devoción al Sagrado Corazón de Jesús(1842), Nuevo septenario de los Dolores de María (1843), El padre de familia (1845), Manual completo del cristiano (1846), Las mujeres de la Biblia (1846), Ensayo crítico sobre las lecturas de la época en la parte filosófica social (1847), Reglas sencillas de cortesía[...] para los niños (1848), Manual de Historia Moderna (1849),Una palabra sobre el doctor don Jaime Balmes (1849), Mujeres de la Biblia(1850), Nuevo novenario para las Hijas de María (1851), Historia de los hechos y doctrina de N. S. Jesucristo (1857), Biografía infantil o sea la niñez de los grandes hombres (1863), Manual de madres católicas (1868), La religión y la política (1870), Las Repúblicas antiguas y modernas (1870)... Como traductor, entre otros textos, publicó,en colaboración con el poeta Manuel de Cabanyes Ballester, la traducción española de Le veglie di Tasso de Giuseppe Compagnoni (1832); bajo el seudónimo de Cándido Amador, El templo de Venus en Gnido de Montesquieu (1835); o los Avisos de la Providencia en las calamidades públicas de San Alfonso Ligorio (1841).

Centrémonos en la obra de la que nos vamos a ocupar en este trabajo, el Juicio crítico de Joaquín Roca y Cornet, texto en cuya portada hallamos los siguientes datos: JUICIO CRITICO / DE / DON LEANDRO FERNANDEZ / de / MORATIN. / COMO AUTOR COMICO. / POR / Inarco Cortejano. / Barcelona: / IMPRENTA Y LIBRERÍA DE A. Y F. OLIVA, / CALLE DE LA PLATERIA JUNTO SANTA MARIA. / 1833. /

Roca compuso su Juicio crítico animado por el concurso que convocó, en 1832, la Real Academia Sevillana de Buenas Letras, -fundada en los tiempos del reinado de Fernando VI, y restaurada, después doce años de cese de actividades, en 1820, en los inicios del trienio liberal- (Aguilar Piñal, 1966),y del que se hizo eco, el 10 de julio de ese mismo año1832, la Gazeta de Madrid, como bien estudió en su día Francisco Aguilar Piñal (1980).Tal concurso, -iniciativa personal del académico Manuel María del Mármol, secundada por el resto de los miembros de la institución-, pretendía premiar, con una plaza de numerario en la propia Academia, al mejor trabajo que se redactase y presentasesobre Leandro Fernández de Moratín como dramaturgo, al mejor «Juicio crítico de Don Leandro Fernández de Moratín como autor cómico, calificando su mérito y comparándolo con el del célebre Molière», que fue el tema obligado aprobado por los académicos, un tema que fue considerado novedoso, digno de uno de los grandes, y más célebres, escritores españoles, y que suponía impulsar la elaboración del 
primer estudio de conjunto sobre la producción teatral de Don Leandro, tras el fallecimiento, cuatro años antes, de éste.

A dicho certamen se presentaron cuatro trabajos. Una comisión, nombrada al efecto, y formada por Manuel María del Mármol, Rodrigo Cañaveral, Manuel de Vos y Silva, el Conde de Cantillana, Francisco de Paula Álvarez, y Rafael de Humara Salamanca-, se ocupó de su examen, y propuso al pleno ordinario de la Academia, celebrado el 20 de diciembre de 1832, que fuese premiado el escrito elaborado por José de la Revilla, afincado en Madrid, que fue titulado Juicio crítico de Don Leandro Fernández de Moratín como autor cómico, y comparación de su mérito con el del célebre Molière. Tal propuesta fue aprobada por unanimidad. El trabajo de Revilla fue leído en la Academia, en solemne sesión pública, el día 4 de enero de 1833, y publicado, posteriormente, en Sevilla, en la Imprenta de Hidalgo y Compañía, en octubre del mismo 1833.

Junto al acuerdo de premiar el trabajo de José de la Revilla la Real Academia Sevillana de Buenas Letras acordó, igualmente, ofrecer al resto de los autores, -tres-, que se presentaron al concurso, ocupar una plaza de académico honorario en la misma institución. Se les concedía el plazo de tres meses para reclamar tal galardón, transcurridos los cuales serían quemadas las plicas con las que los escritos se habían presentado al certamen. De los tres participantes tan sólo uno se dio a conocer públicamente y reclamó el nombramiento de académico honorario. Se trató del capitán de artillería y profesor de matemáticas Juan de Dios Gil de Lara, que había presentado su Juicio acerca de Don Leandro Fernández de Moratín, conservado, hoy, en manuscrito, en la Biblioteca Nacional de España (Ms. 3710 y 19627), y que había traducido al español El Avaro de Molière. De los dos restantes nada más se supo por entonces, aunque hoy sus nombres están identificados. Uno de ellos fue José Amador de los Ríos, cuyo texto quedó inédito hasta 1966, en que fue publicado por Pierre Guenoun (1966), ${ }^{3}$ tras localizarlo en los sótanos de la Universidad Central de Madrid. El otro no fue sino el barcelonés Joaquín Roca y Cornet, quien había presentado su Juicio crítico de don Leandro Fernández de Moratín, como autor cómico, que nos ocupa, obra que dio a las prensas en Barcelona, en la Imprenta y Librería de A. y F. Oliva, en 1833, firmada con el seudónimo de Inarco Celenio, como vimos.

\footnotetext{
3 Amador de los Ríos utilizó en 1848 su trabajo como Memoria de Licenciatura, presentada en la Universidad de Madrid.
} 


\section{LAS VALORACIONES DE JOAQUÍN ROCA Y CORNET}

\subsection{Los preliminares}

El Juicio crítico de don Leandro Fernández de Moratín, como autor cómico tiene un carácter eminentemente encomiástico. Tal característica queda puesta de manifiesto ya desde las primeras líneas de su redacción:

No es posible resistirse al deseo de tributar á un español benemérito un justo homenage de admiracion y de reconocimiento, aunque por otra parte no permitan las fuerzas prestarle un tributo digno de él, y de la nacion generosa á que pertenece. Confieso ingenuamente que esta es mi situacion.(Roca, 1833: 5)

No es extraño tal deseo de tributar un homenaje a Don Leandro, dado el prestigio que ya había alcanzado por entonces, y lo relativamente próxima que se hallaba la fecha de su fallecimiento. Ante ello, no es rara la captatio benevolentiae que se incluye en las líneas subsiguientes:

Arrédrame mi insuficiencia para tan elevada empresa; mi pincel no puede trazar mas que borrones informes comparados con los cuadros brillantes y bien acabados á que se ha hecho acrehedora su ilustre memoria. Permítaseme este ligero desahogo, ó si se quiere atrevimiento, yo no aspiro mas que al placer de ensayar un rudo bosquejo en elogio del príncipe de nuestros dramáticos modernos y de uno de los literatos que honran á muestro siglo. Este es el único objeto que guia mi pluma, y cualquier otro sentimiento que deslumbrase en este instante mi razon, pudiera justamente graduarse de necia temeridad ó de un esceso de amor propio.(Roca, 1833: 5-6)

El objetivo que pretende alcanzar Joaquín Roca con su escrito, no es sino resaltar los grandes méritos que posee Leandro Fernández Moratín como compositor de obras dramáticas, «género á que dedicó particularmente sus largas vigilias y felices disposiciones, y que le mereció una corona inmarcesible en el templo de nuestros ilustres genios»(Roca, 1833: 6), sin hacer relación detallada del resto de sus muchos y notables méritos, personales y profesionales (esmerada formación, premios literarios que fue obteniendo, el talento y genio del que estaba dotado, su grandeza de alma, la buena reputación de la que gozó pese a «los ladridos de una crítica mordaz y envidiosa con que los oscuros émulos engrandecen á pesar suyo el verdadero mérito» (Roca, 1833: 7), su despego de los honores mundanos, su amor por la vida retirada, el placer que encontraba en la creación literaria...). 
No obstante, pese a ser esa su intención, el barcelonés considera necesario no centrarse directamente en el análisis de la producción dramática de Don Leandro. Para entender la verdadera magnitud de su aportación a las letras hispanas y universales, considera necesario estudiar, antes, su labor como historiador del teatro de su país, y el análisis que transmitió de la situación en la que éste se hallaba en los años previos al advenimiento de la Ilustración. Destaca, elogiosamente, que hizo su trabajo «Sacudiendo el polvo de antiguos y olvidados manuscritos y documentos, y conciliando el árido trabajo de penosas investigaciones con un criterio delicado, un gusto esquisito y la profunda inteligencia del arte» (Roca, 1833: 9).

Roca se centra en el examen del discurso preliminar que abre la edición de las obras teatrales de Leandro Fernández de Moratín, y va resaltando los datos históricos que allí fueron insertados. Así, la ausencia de documentación que pueda demostrar la existencia de representaciones teatrales religiosas antes del siglo IX. Las noticias sobre representaciones dramáticas en la época de Alfonso X, y el progreso de éstas en los años de Juan II, de los Reyes Católicos, de Cisneros, y su gran avance con la aparición de la imprenta, y a lo largo del siglo XVI, en el que el teatro se afianza fuertemente en España. La decadencia de la poesía dramática en la segunda mitad del siglo XVI, reflejo de la decadencia en la que va cayendo toda la sociedad del momento en general:

A mitad del siglo XVI empieza la decadencia de nuestra poesía que camina siempre á la par con la civilizacion. La falta de protectores y estímulos, la indolencia de los monarcas subsiguientes, el mal gusto diseminado por la lectura de los libros caballerescos, y los conocimientos humanos reducidos al solo estudio de las ciencias abstractas y lucrativas; fomentaron la absurda aficion á fábulas y prodigios increibles, y acabaron de corromper el gusto y destruir la aficion á la verosimilitud teatral. Pasaron de los templos á los teatros las comedias religiosas, y los augustos misterios de la Fé, sirvieron para divertir á un pueblo grosero é ignorante con la ridiculez y estravagancia de la invencion.(Roca, 1833: 10)

La aparición de ciertos escritores que lograron mantener calidad en la creación dramática, -pese a las adversas circunstancias existentes-, «hasta la aparición del inmortal Lope de Vega» (Roca, 1833: 11). Y toda esta labor la va haciendo Moratín con

escogida erudicion de las anotaciones, que ilustran varios pasages del discurso, el tino, el dicernimiento y la gracia, con que clasifica las primitivas producciones del género dramático, no descuidando el hacer notar aquellas bellezas esparcidas que no ofrecen sino vestigios de genio y falta de correccion; la oportumidad con que cita á nuestros mejores críticos para apoyar é ilustrar sus opiniones, y aquel fondo 
general de conocimientos en tantas otras materias; sin el que no es posible tratar alguna magistralmente.

En el ecsamen de las piezas anteriores á Lope de Vega, campea una fina y juiciosa crítica amenizada con el gracejo al referir sus argumentos ridículos; y los oportunos elogios con que nunca deja de anunciar los aciertos son garantes irrecusables de su imparcialidad.(Roca, 1833: 11)

El autor catalán concluye esta parte de su trabajo recordando que Don Leandro dedica parte de su introducción a recopilar «algunas noticias en resumen de la vida de los autores mas notables [Juan del Encina, Vasco Díaz Tanco, Bartolomé Torres Naharro, Lope de Rueda, Juan de la Cueva...] y la insercion de varias muestras de sus mejores trozos» (Roca, 1833: 11-12).

Roca, antes de centrar su Juicio crítico en el examen de la producción dramática de Moratín, desea hacer una valoración previa de los escritos teatrales de Molière, antes de comparar la labor de esos dos grandes dramaturgos. Piensa que el francés es uno de los grandes creadores de todos los tiempos. Juzga que la «lectura reflecsiva de sus comedias puede suplirá la esperiencia, pues no ha pintado ridiculeces locales y pasageras, sino al hombre mismo que no muda jamás» (Roca, 1833: 13). Molière en su teatro pinta cualidades y defectos de los hombres, pero de tal modo que logra suscitar la risa en el espectador, aunque pueda sentirse reflejado en las lacras que presentan los propios personajes de ficción. Consigue que sus obras dramáticas agraden tanto siendo leídas como siendo representadas, pues «Cuanto mas le penetramos mas le queremos, á medida que le vamos estudiando crece nuestra admiracion, y aunque le reprehendamos en algun punto, al fin nos vemos precisados á pensar como él, porque ya le conocemos mejor»(Roca, 1833: 13):

Moliére es con preferencia el autor de los hombres sensatos y de los viejos; su esperiencia resalta en sus observaciones y su memoria se halla en su genio. Observaba mucho por inclinacion natural, y este es seguramente el primer secreto de su arte; pero para observar como él sería preciso tener sus mismos ojos. Este hombre que escribió con tanto chiste y gracejo era naturalmente melancólico, y muchas veces los mismos cuyos yerros y flaquezas ponia en ridículo, eran mas dichosos que él. (Roca, 1833: 14)

En el comediógrafo francés, juzga, se cumplen a la perfección las reglas que ha de respetar el buen dramaturgo: la buena imitación de la naturaleza, el reflejo en sus obras de las cualidades positivas y negativas del ser humano, la correcta pintura de la sociedad, la 
posesión de un genio capaz de estudiar al hombre con exactitud, mostrando maestría en trasladar a sus textos pasiones fuertes, espíritus convulsos, el odio por las malas acciones y el amor por la virtud. «Conocia el arte de conciliar la gravedad de la razon con el chiste de la sátira, y hablando en general con todos los hombres, dejaba marcado en sus producciones el genio particular de su pueblo» (Roca, 1833: 21-22). Son cualidades, concluye Roca, que comparten Molière y Moratín.

\subsection{El estudio del teatro moratiniano}

\section{2. 1. Molière y Moratín}

Para Joaquín Roca y Cornet, la obra de Fernández de Moratín se halla en la misma línea en la que se encontraba, anteriormente, la de Molière, con quien aquél muestra concomitancias. Don Leandro, según él, estaba «Dotado [...] de cualidades tan eminentes como Molière, pero [era] menos atrevido» (Roca, 1833: 22). Él supo adquirir, antes de iniciar su labor como dramaturgo, una sólida formación, basada en el estudio de la antigüedad, y de la creación de su tiempo, y, aunque tomó a Molière como un referente digno de ser imitado, fue siempre bien consciente que el autor francés y él escribían para públicos muy distintos, por lo que él tenía que adaptarse en sus textos a las circunstancias de su país, y de los espectadores que iban a convertirse en los receptores inmediatos de sus textos. Hubo de tener en cuenta el contexto teatral en el que iba a aparecer su teatro, considerando que, si bien

se hallaban desterrados en España los absurdos vestigios de las farsas, autos, entremeses y comedias mágicas de los primeros siglos de su civilizacion, predominaba todavía un gusto decidido al embolismo dramático, á la chocante caricatura de los caractéres, á los desenlaces maravillosos é increibles, y á la indecorosa licencia teatral, que convertia en escuela de corrupcion la que debia serlo de costumbres. El sabio y sensato Iriarte habia dado antes que Moratin, un grande paso hácia la verdad y la correccion cómica, y pudiera decirse que merece partir con él el lauro de reformador de nuestro teatro, bien que el último le aventaja notablemente en gusto, en perfeccion y en delicadeza. El artificio, regularidad y buena moral del Señorito mimado y de la que puede llamarse su hermana la Señorita mal criada, bien que inferior á la primera en invencion é intriga, manifiestan un conocimiento profundo del corazon humano, y son recomendables ambas piezas por la maturalidad y correccion de su diálogo. Moratin, pues, no desconfió enteramente de poder introducir con el tiempo en el teatro toda la cultura y perfeccion de que es suceptible en un público civilizado.(Roca, 1833: 22-23) 
Sabía que un pueblo que había dado en épocas anteriores una literatura que referente para toda Europa, no ofrecería resistencia a obras escritas y montadas con calidad. «Conocia que solo faltaba quien se las hiciese notar y apreciar como era debido, confiaba sobre todo para el feliz écsito de su empresa en el voto de una parte culta y numerosa de la sociedad, en la que el hábito viciado de la multitud no habia destruido el gusto de lo arreglado y de lo bello» (Roca, 1833: 23).

Moratín quiso hacer un teatro para su pueblo, por lo que se empeñó en conocer bien a éste, y constató, en los diversos viajes que emprendió, las diferencias existentes entre su país y los otros pueblos europeos del momento.

El carácter español, suceptible de todas las pasiones fuertes y profundas, grave sin ostentacion, reservado y pundonoroso, no participa de la veleidad francesa, de la ligereza italiana, ni de la taciturnidad sombría que constituye el fondo del carácter inglés. Festivo con moderacion no desdeña el chiste y el gracejo que le es en parte natural, $\mathrm{y}$ aun le busca en las obras destinadas á corregirle. Tal vez ninguna nacion ha tenido tantos autores, que se hayan burlado con mas gracia de sus errores y flaquezas, y cuyas burlas haya ella recibido con mas docilidad. La obra maestra de la sátira y de la burla, que admira el mundo, nos pertenece, y cuanto mas nos echó en cara la desatinada porfía hacia las lecturas caballerescas, tanto mas fué aplaudida y provechosa. Con estas ventajas, pudo Moratin unir la observacion de la naturaleza, con el peculiar estudio del carácter nacional, y pintar en sus comedias al pueblo mismo para quien escribia, como habia hecho Molière en el suyo.(Roca, 1833: 23-24)

Con el fin de adaptarse a los gustos de su público convirtió la cualidad de la decencia en la base de sus creaciones, con el fin de nunca ofender en ningún caso a los espectadores de su nación, que nunca hubiesen aceptado licencias que se tomaba habitualmente Molière en sus creaciones y en los montajes de las mismas, licencias que eran bien recibidas por los receptores franceses, que se vieron reflejados en sus obras, retratados en la escena, y, así, «Cada uno se rió de sí mismo, y aplaudió al actor que le remedaba. No el vulgo precisamente, la parte mas culta de la sociedad en la que cundia este defecto, no pudo dejar de reconocer el imperio de la verdad, y correrse de su error sin sentir picado el amor propio»(Roca, 1833: 27).

En el teatro de Molière, explica Roca, -como vemos en La escuela de los maridos, adaptada después por Don Leandro con éxito y corrección-, «Las escenas son claras, naturales, interesantes y bien unidas, y el desenlace es de los [...] mas perfectos del teatro francés» (Roca, 1833: 27-28). En sus comedias el autor galo 
desplegó aquella filosofía profunda que descubre los pliegues mas recónditos del corazon humano, y que bajo la sazon de las chanzas y donaires se propone curar aquellas dolencias secretas de su alma que con frecuencia le hacen vivir desgraciado. Por tales serán reputadas siempre entre los inteligentes el Misántropo, el Avaro y el Tartufo.

Una cierta aversion á los hombres por sus vicios que viene á convertirse en una pasion frenética é insuportable, alimentada por los sinsabores que ofrece á cada paso la sociedad y fomentada por el amor propio, es un vicio que no deja de encontrarse en cierta clase de hombres descontentadizos é intolerantes que de todo se fastidian, que todo lo condenan y no saben tolerar los mas ligeros defectos. Molière une á la crítica parcial de un hombre severo é inflecsible la crítica universal del género humano; poniendo en feliz contraste al inecsorable filósofo con su condescendiente amigo, que sufre las faltas de los hombres por la necesidad que tiene de vivir con ellos.(Roca, 1833: 29-30)

Pese a sus innegables virtudes el teatro de Molière, concluye el intelectual catalán, contiene, igualmente, ciertos defectos, explicables, fundamentalmente, por la circunstancia de que cuando el creador francés «se aparta del verdadero objeto de la poesía dramática, cae muy facilmente en el defecto de la inverosimilitud» (Roca, 1833: 34).

\section{2. 2. Las comedias de Don Leandro}

Joaquín Roca y Cornet, tras su examen del teatro de Molière, relacionándolo con el de LeandroFernández de Moratín, se centra en el análisis de la obra dramática del autor español, aclarando que no sólo va a destacar los aspectos más positivos que tiene su creación, sino que va, igualmente, a ocuparse, sin despreciarlas, de «las, observaciones dictadas por la crítica mas severa», intentando, en todo caso, mantenerse «en un término medio entre sus censores y sus apologistas» (Roca, 1833: 35), advirtiendo, también, que sus palabras no dejan de ser una opinión personal, nunca un «fallo» (Roca, 1833: 35).

Empieza su tarea abordando El viejo y la niña, la primera comedia dada a conocer por el creador madrileño, según recuerda el barcelonés, injustamente tratada por la crítica, que arremetió contra ella. Las acometidas contra la pieza procedieron de personas que sólo apreciaban textos llenos de enredos, por lo que rechazaban composiciones de factura más sencilla, a las que tildaban de parcas en invención, pese a que «la sencillez de un plan interesante es una de las bellezas de toda pieza dramática, pues que la complicacion cuanto mas artificiosa mas se aparta de lo natural, que es el tipo de lo bello en toda especie de 
imitacion. Cuando á esta sencillez se añade la progresion de los lances, la sostenida diversidad de los caractéres, la naturalidad y lozanía del diálogo, donde está la pobreza de invencion?» (Roca, 1833: 35). El catalán juzga que

El desenlace aunque parezca austero y melancólico, y se aparte de aquella flecsible y cómoda moralidad que, segun dice el mismo autor, es ya peculiar de ciertas clases en los pueblos mas civilizados de Europa, con dificultad podia substituirse por otro que conciliase la sucesiva tranquilidad de ambos esposos con la verosimilitud y decoro teatral. [...] En fin, si el autor á pesar de la maestría que descubre en toda la pieza no atinó en llevarnos á un desenlace mas cómico, no debemos olvidar para gloria y disculpa suya que era la primera de sus comedias, y que no fué aun tan feliz Molière en sus primeros ensayos. (Roca, 1833: 36)

Y concluye afirmando que «Moratin, pues, dió en su primer ensayo una prueba admirable, asi de su genio como de sus profundos conocimientos en el arte dramático. Sobrepujando en naturalidad y correccion á cuantos le habian perdido, abrió á nuestros ingenios una senda dificil, pero asequible con la asiduidad y la aplicacion» (Roca, 1833: 37-38).

Dos años después del ofrecer El viejo y la niña, Don Leandro creó y difundió uno de sus grandes textos «la inmortal y esquisita pieza en dos actos, titulada: la Comedia nueva ó el café»(Roca, 1833: 38). En ella «Su recomendable objeto era presentar el lastimoso estado del teatro, en la época en que fué escrita, y purgarle de los abusos introducidos, tanto por los malos autores y corruptores de la poesía dramática, como por los mismos representantes. Esta invencion singular hace doble honor á Moratin, como á crítico y como á poeta»(Roca, 1833: 38). De La comedia nueva Roca destaca

las inimitables bellezas de que abunda, la delicadísima naturalidad del diálogo [...], el interés y el verdadero cómico de sus lances, la sencillez de su plan, y la esquisita graciosidad con que se reprenden los vicios literarios de que mas adolecia nuestra escena. El conocedor imparcial, siente el encanto de una pieza tan oportuna, tan bien combinada y tan natural, que dificilmente atina con todas las causas de una impresion tan deliciosa. Aplicable esta comedia particularmente á una época determinada, es una leccion escogida de gusto y de buen sentido en todos los teatros del mundo civilizado; su mérito no perecerá jamas, varios estrangeros le han tributado la admiracion de que es digna, aunque es muy dificil, sin ser español conocer todo lo que vale. (Roca, 1833: 38-39)

De ella quiere resaltar la originalidad y belleza de su composición, su gran sensibilidad y el buen gusto que rezuma, y la importante lección moral que traslada a los espectadores. Y 
considera que, si se desea buscarle algún defecto, no podrá ser encontrado ni en el trazado general del argumento, ni en los personajes ni en su acción, y tan sólo a algunos detalles sin mayor importancia podrían hacerse algunas objeciones, aunque siempre terminan predominando las escenas dotadas de «golpes maestros» y de una «preciosa originalidad»(Roca, 1833: 41), y el gran conocimiento que muestra del hombre, de su forma de ser, de sus flaquezas.

En El barón, explica el barcelonés, quiere Moratín reflejar ciertos defectos que se detectan en la sociedad española del momento, pues en ésta

como en todas partes la vanidad de parecer mucho y de emparentar con sugetos de alto rango es en no pocos una pasion irresistible, y para lograrlo se dejan arrastrar de ilusiones lisongeras á las que sacrifican con frecuencia hasta su verdadero bien estar. Abunda tambien por desgracia la clase de hombres tunantes embusteros que se venden por gente de distincion, y embobando con su charlatanismo á los crédulos é ignorantes, buscan como sacar partido de sus engaños é imposturas. (Roca, 1833: 41-42)

Juzga que es la pieza con menos méritos de todas las compuestas por el dramaturgo madrileño, aunque ello no quiere decir que carezca de aspectos positivos:

Sin embargo de ser la pieza inferior entre todas las publicadas por él, no carece de mérito y de bellezas. Su fábula es interesante, sencilla verosimil; abunda en sales y gracias cómicas, y encierra un fondo precioso de verdad é instruccion. El métro es fácil y fluido, el diálogo animado, los caractéres forman un juego bien sostenido.

Se ha objetado á la perfeccion de esta pieza la falta de enredo, y no hay duda que desde un principio conocemos ya las artimañas del Baron, y solo deseamos saber con que ardid saldrá ese bribon del aprieto en que se va metiendo, y esto es lo único que mantiene la curiosidad de los espectadores. Pero la clase á que pertenece esta pieza no permite que se la juzgue estrictamente por las reglas de la alta comedia, y debemos alabar la habilidad con que el autor supo formar de una zarzuela desfigurada mal zurcida y alterada por manos poco espertas, una pieza arreglada y de buen gusto.(Roca, 1833: 42-43)

En su argumento se va a insertar «un cuadro risueño de la gazmoñería mugeril», «el fatal efecto de una educacion en estremo rígida y opresora», un perfecto estudio del «carácter de una solapada mogigata, es decir, de una niña á quien el rigor de un padre áspero é 
inflecsible obliga á ocultar bajo apariencias de virtud todas las pasioncillas de su edad, y finjirvocacion de claustro, viciándose asi un natural que bien dirigido hubiera sido virtuoso». Y todo ello haciendo uso del paralelismo y el contraste, pues con el fin de «resaltar mejor la hipocresía de la hija y la bajeza de un padre, interesado en su encierro por la esperanza de heredarla»se va a contraponer a estos personajes otros dos que intervienen en la obra:una «prima suya á la que una educacion dada por un padre prudente y discreto ha infundido una sólida virtud, y una amable franqueza» (Roca, 1833: 44). Pese a todo a esta comedia se le puede poner alguna objeción, pues

si bien en su lectura no he sabido advertir la mas remota sombra de inmoralidad y falta de decoro, su representacion sin embargo pudiera producir efectos tal vez contrarios á las sanas y juiciosas miras del autor. El público por mas ilustrado que se suponga, no posee en general el grado de talento y de discrecion necesario para discernir como corresponde el verdadero objeto de ciertos avisos muy saludables, si se quiere, pero muy delicados en su aplicacion. Confunde facilmente los estremos con el medio, y no tiene formada de la virtud una idea tan ecsacta que no tome con frecuencia lo aparente por lo real, creyendo ver en la crítica de la hipocresía la de la sólida piedad. Las falsas ó superficiales ideas de religion, de que muchísimos adolecen, hace muy arriesgado el empeño de hacerles conocer sus abusos en un drama, cuando apenas basta la ecsactitud de una cátedra, y no es la hipocresía religiosa el vicio que en el dia causa mas perjuicios á la sociedad. La verdadera religion es muy preciosa paraque se esponga á ser confundida con la bellaquería, por una mala interpretacion, y es muy sublime su doctrina para esponerla al menor peligro de aplicarla mal.(Roca, 1833: 47-48)

El sí de las niñas es presentada como modelo digno de imitación, como prototipo «de la belleza, y de la naturalidad en el drama» (Roca, 1833: 48), como obra inmortal, capaz por sí misma de dar gloria imperecedera a su creador. Ha sido traducida a casi todas las lenguas europeas, y admirada por todas las personas dotadas de buen gusto y buena sensibilidad, y ha sido

objeto de envidia y de mordacidad para todos los que echan menos en ella complicacion, embrollo y lances estraordinarios y asombrosos, es la pieza encantadora que corona las producciones dramáticas originales de nuestro poeta. En ella escogió Moratin un plan sencillísimo, pero dificil de imitar por su misma sencillez; precindió del artificio de la fábula, y solo conservó el nudo indispensable á la accion, dando toda la importancia á los caractéres y á los sentimientos. Su objeto es nada menos que corregir uno de los errores mas contrarios á la prosperidad 
social, el abuso intolerable de no dejará las niñas la libertad de elegir esposo. Descubre con vivísima gracia lo que debe fiarse en aquel sí balbuciente y equívoco que les arranca la severidad de unos padres á quienes miran como jueces inflecsibles ó tiranos, en lugar de tiernos y amorosos confidentes, y manifiesta la ligereza con que éstos aseguran la voluntad y resolucion de sus hijas, y el engaño en que viven sobre sus verdaderos sentimientos.

Parece que esta comedia toca ya al último punto á que puede llegar la destreza del arte, para ocultarse y producir por medio de la ficcion los efectos de la verdad. Cuanto mas ilustrado es el espectador, con mas facilidad se entrega al placer de una ilusion tan poderosa, tan grata, que casi vale tanto como la realidad misma. (Roca, 1833: 48-49)

En ella el espectador de olvida de que se halla ante una obra de ficción y se sumerge en el argumento, como si fuera uno más de los personajes que se incluyen en el mismo, convirtiendo en realidad vivida por él los sucesos que se desarrollan en la pieza y los personajes a los que se les encarga protagonizarlos, quedando hondamente conmovido por todo. En ella todo resulta interesante para el auditorio. La razón es que allí nada se deja al azar. La composición está milimetrada en todas sus partes, insertando siempre los ingredientes que son precisos para facilitar el logro de los objetivos que persigue su creador. Naturaleza y arte se dan aquí la mano con una perfección difícilmente alcanzable y difícilmente alcanzada por otros escritores.

Roca Cornet cree igualmente digna de ser resaltada la labor realizada por Moratín como traductor y adaptador de textos dramáticos extranjeros (Cañas, 1999a, 1999b). De hechoconsidera que

las piezas que [...] escogió y arregló despues para nuestro teatro, son un modelo que deberian tener presente cuantos se ocupan en traducir obras dramáticas. Manifestó Moratin que con este género la traduccion es mas dificil de lo que se cree, que para traducir bien una comedia se necesita ser casi capaz de hacerla original, que rarísima vez puede trasladarse con oportunidad toda entera, como sucede en obras de otra clase, sin acomodarla á nuestros usos, costumbres y genio, haciendo con pulso aquellas variaciones indispensables que sin menoscabo del mérito y la gracia del original, den al drama el aire y el colorido propio de nuestra nacion.(Roca, 1833: 51)

Recuerda, después, las obras que tradujo y adaptó al español. Así, La escuela de los maridos, cuya versión a su lengua materna juzga equiparable, en bondades, al original de 
Molière, hasta el punto de que «la amoldó [...] con atinado pulso segun el gusto español, y la hizo española»(Roca, 1833: 52). Así, El médico a palos, en la que «tuvo Moratin que cambiar y substituir mucho para acomodarse al verdadero gracejo castellano. Moderó la libertad de algunas espresiones que habrian repugnado á la gravedad y al decoro español, y mas aun al genio del pais para cuyo teatro fué escrita» (Roca, 1833: 53). En general, el barcelonés considera que el autor español consigue con su trabajo ofrecer a los interesados obras traducidas y adaptadas que llegan a igualar en calidad a las francesas de las que proceden:

Moratin vertia sus comedias á la española, y aunque los vicios se parecen en el fondo en todos los paises, deben sin embargo acomodarse las modificaciones al genio nacional, paraque los reconozcamos por nuestros. De lo contrario el drama no producirá el efecto que debe producir. Nos reimos de las flaquezas de otra sociedad, y aunque nos toque de cerca la burla nunca creemos vernos retratados en ella.(Roca, 1833: 54)

Es prueba palpable del gran valor que tiene el trabajo realizado, como intelectual, como dramaturgo y como traductor experto y conocedor de su oficio, por Leandro Fernández de Moratín.

La obra del escritor madrileño, comparada con la producción aportada por el dramaturgo francés Jean-Baptiste Poquelin, Molière, no queda relegada a una segunda categoría. Roca considera al español un muy digno creador, capaz de parangonarse, sin desdoro, en sus escritos, con los más importantes y reputados autores del respetado y admirado, en su época, país galo, entre ellos el propio Molière, con el que había de ser comparado, según la convocatoria del concurso hecha pública por la Real Academia Sevillana de Buenas Letras, en los trabajos que a éste fuesen presentados. Entre ambos comediógrafos hay puntos de contacto, pero también divergencias. Todo explicable por la diferencia de carácter y temperamento existente entre los dos. Por ello concluye el autor catalán con las siguientes palabras que, por su interés, no nos resistimos a reproducir, aunque seleccionadas, pese a su extensión:

Segun pues el juicio que he podido formar de ellos por la detenida lectura de sus obras, y atendidas las observaciones de sus críticos, concluiré con indicar, que concediendo á entrambos disposiciones no comunes para sobresalir en el género cómico, genio, talento, y estudio del hombre y de la sociedad, Molière me parece mas fecundo, y Moratin mas delicado; el primero preferible en los caprichosos 
estremos del ridículo, atrevido, picante, y alguna vez con demasía acre y bufon, el segundo mas correcto, mas arreglado y mas circunspecto. En las intrigas del primero hay mas arte y complicacion, en las del segundo mas sencillez y regularidad. Molière pinta con frecuencia un carácter en un solo rasgo. Moratin no tiene el pincel tan vivo, pero sus coloridos son mas finos. Ambos [...] son admirables en la descripcion de las costumbres, pero Molière se acerca mas á las libres gracias de Plauto, y Moratin á las modestas bellezas de Terencio, si empero faltar la gracia, la sal y el donaire cómico. [...] Moratin sabia prevenir mejor los desenlaces en lo que [...] Molière acostumbra ser menos feliz, aun en las piezas mas [...] trabajadas y en las que puso mayor esmero[...]. Moratin es menos precipitado no tan violento, y guarda en toda la progresion del drama mas enlace y mas naturalidad, Molière no economiza tanto los personages. Moratin parece que los escoge ajustados para la accion, y pone mas cuidado en caracterizar hasta los subalternos.

No podemos juzgar del mérito de Molière por todas sus piezas, sino por aquellas en cuya perfeccion empleó sin obstáculos todo su conato. En algunas cedió algo al gusto del público y los vicios dramáticos de su tiempo; en otras obligado por órdenes espresas del Rey, sacrificó un tanto las reglas al aparato escénico, y á la magnificencia cortesana. [...] Moratin [...] [no se] vió precisado á guardar las consideraciones del primero, pero tuvo el mérito de hacer frente á inveterados abusos literarios, y oponer con valor las gracias del órden y del decoro al ascendiente poderoso del mal gusto, del capricho y de la rivalidad. Molière tuvo la ventaja de aprovecharse de las instrucciones que de todas partes le enviaban las gentes de tono, que se complacian en verse retratados por su pincel con sus propios defectos y estravagancias. Moratin no se vió tan abrumado y no tuvo por ayuda otros maestros que modelos y observacion. Sacó sus asuntos del fondo de la sociedad en que vivia, y nunca tuvo lugar ni se vió en la precision de contentar de una vez á sus instructores $[\ldots]$.

Moratin es admirable por la correccion, frescura y suelta naturalidad de su diálogo, y el gustoso sabor dramático de su estilo, en lo que nadie hasta ahora le ha igualado, es una de sus perfecciones.

Sin necesidad pues de quitar á cada uno lo que le corresponde Molière siempre tendrá la gloria de ser entre los franceses y aun entre los modernos el que ha dado á conocer la verdadera comedia, y Moratin el que mas de cerca le ha seguido en la invencion dramática aventajándole en la culta regularidad. ¡Moratin! Digno y precioso modelo para los españoles y para cuantos aspiren en la dificil senda que él ha seguido á la inmortal corona que le prepara la agradecida prosperidad. (Roca, 1833: 54-56, 57-58)

\subsection{El contexto de un trabajo: bases para una correcta valoración}

El Juicio crítico de don Leandro Fernández de Moratín, como autor cómico es un escrito académico, compuesto en un contexto concreto que ejerce un influjo muy directo 
sobre su composición, la condiciona y explica los caracteres que le han sido conferidos. Como vimos, se escribe para ser presentado en un concurso convocado por la Real Academia Sevillana de Buenas Letras sobre el tema que le sirve de título, y al que habían de ajustarse, necesariamente, todos los participantes, un concurso que preveía la lectura pública del trabajo que resultase ganador en una de las reuniones de la institución convocada expresamente para ello. De ahí que presente ese aspecto de discurso que observamos al realizar su lectura y análisis, y contenga los recursos propios de una transmisión oral que detectamos en su redacción.

Por otro lado, se redacta en el contexto de la reivindicación de personajes progresistas, liberales, de la Ilustración, que habían sido perseguidos por sus ideas en los años del reinado absolutista de Fernando VII, y que son recordados y ensalzados a partir del llamado Trienio Liberal, o Trienio Constitucional (1820-1823), periodo que siguió al sexenio absolutista (1814-1820), y en el que el monarca hijo y sucesor de Carlos IV es obligado a jurar e instaurar la Constitución de 1812, la Constitución de Cádiz, antes de que la denominada Década Ominosa (1823-1833) se encargase de sustituirlo, instaurando de nuevo el gobierno absoluto del conocido como Rey Felón. Son, desde 1820, años de rescate de autores célebres, -como Juan Meléndez Valdés, o el propio Leandro Fernández de Moratín-, que impulsaron las reformas en su país, e incluso llegaron a ocupar puestos de responsabilidad en el reinado de José I Bonaparte, por lo que fueron tachados de colaboracionistas con el invasor galo, y de afrancesados, y fueron vilipendiados y perseguidos tras el final de la Guerra de la Independencia, llegando muchos a morir en el exilio. Fue un rescate que adquirió nuevos bríos, nuevos impulsos, nueva fuerza, en los momentos finales del reinado de Fernando VII, previos al reinado de Isabel II, época en la que se convoca el concurso sevillano al que antes nos hemos referido. De ahí el carácter eminentemente apologético y de exaltación, incluso apasionada, de Don Leandro y su obra que posee el Juicio crítico que a él le dedica Joaquín Roca y Cornet.

La valoración que podemos hacer de la labor realizada por el intelectual, autor y periodista barcelonés en su discurso, no puede ser, en general, sino positiva. Redacta, con apasionamiento, pero también con corrección, suapología de la figura y la producción de Leandro Fernández de Moratín que se suponía debía ofrecerse a sus receptores, según las bases del concurso al que se presentó y que deseaba, y esperaba, ganar. Si sus resultados fueron o no superiores a los contenidos en el escrito que finalmente resultó vencedor en el 
certamen, el Juicio crítico de Don Leandro Fernández de Moratín como autor cómico, y comparación de su mérito con el del célebre Molière, de José de la Revilla, sólo podría constatarse si efectuásemos un cotejo entre este texto y el Juicio crítico de Roca. Pero esa es una tarea que no tiene cabida en la investigación que ahora concluimos. Tal vez en otro momento tengamos ocasión de afrontarla.

\section{Bibliografía}

Aguilar Piñal, Francisco. La Real Academia Sevillana de Buenas Letras en el siglo XVIII. ${ }^{4}$ Madrid: Consejo Superior de Investigaciones Científicas, 1966

Aguilar Piñal, Francisco. "José de la Revilla, crítico de Moratín". Coloquio Internacional sobre Leandro Fernández de Moratín. Bolonia, 27-29 de octubre de 1978. Bolonia: Piovan, 1980. 9-21.

Alcalá Galiano, Antonio. Historia de la Literatura española, francesa, inglesa e italiana en el siglo XVIII. Madrid, 1845. 442-452.

Anónimo. "En elogio de Don Leandro Moratín". Correo de Madrid, 367, 5 junio (1790a): 119-120.

Anónimo. "Soneto en elogio de El viejo y la niña". Memorial Literario, junio (1790b). 311.

Bretón de los Herreros, Manuel. "A Moratín”. El Clamor Público, 9 de julio de 1848.

Cañas Murillo, Jesús (1999a). "Leandro Fernández de Moratín, traductor dramático". En La traducción en España (1750-1830). Lengua, literatura, cultura, Francisco Lafarga (ed), Lérida: Universidad de Lérida, 1999a. 463-475.

Cañas Murillo, Jesús "Leandro Fernández de Moratín, traductor y adaptador dramático". Anuario de Estudios Filológicos XXII, (1999b): 73-98.

Elías de Molins, Antonio. "Roca y Cornet D. Joaquín" Diccionario biográfico y bibliográfico de escritores y artistas catalanes del siglo XIX (Apuntes y datos). 1889-1895. Barcelona: Imprenta de Fidel Giró, vols.2, (II), 1895. 470-482.

Gil de Lara, Juan de Dios. Juicio acerca de Don Leandro Fernández de Moratín. Manuscrito de la Biblioteca Nacional de España (Ms. 19627). España: Biblioteca Nacional de España 1833.

Gil Novales, Alberto. "Roca y Cornet, Joaquín (1804-1873)". 2018. http://www.mcnbiografias.com/app-bio/do/show?key=roca-y-cornet-joaquin

Guenoun, Pierre. "Un inédit de José Amador de los Ríos sur Leandro Fernández de Moratín". En Mélanges à la memoire de Jean Sarraihl, I, Paris, 1966. 397-412.

Mesonero Romanos, Ramón. "El sepulcro de Moratín en el cementerio de París". Semanario Pintoresco Español, 1841. 305-306.

Napoli Signorelli, Pietro. Storia critica de' teatriantichi e moderni. Nápoles: Stamperia Simoniana, 17775 .

\footnotetext{
${ }^{4}$ Reimpreso en facsímil, en Sevilla: Colegio Oficial de Aparejadores y Arquitectos Técnicos de Sevilla, 2001).

5 Este texto fue objeto de ediciones sucesivas corregidas por su autor, publicadas entre 1787-1790, la segunda edición que constó de seis volúmenes -Napoli, Vincenzo Orsino-, y en 1813 la tercera edición, distribuida en diez tomos -Napoli, Vincenzo Orsino-; hubo una edición incompleta, en dos volúmenes, titulada, igualmente, Storia critica de' teatriantichi e moderni, y publicada en Venecia, en la Tipografia Pepoliana, entre 1794 y 1795.
} 
Napoli Signorelli, "La commedia nuova. Commedia in dueatti in prosa tradotta dallo spagnuolo da Pietro Napoli-Signorelli”. Opusculi Vari, I-IV, Nápoles: Stamperia Orsiniana, 1792-1795. 1-54.

Pérez de Acevedo, Luciano. "En el aniversario de la muerte de Moratín. Soneto" .Semanario Pintoresco Español, 1851. 88.

Revilla de la José. Juicio crítico de Don Leandro Fernández de Moratín como autor cómico, y comparación de su mérito con el del célebre Molière. Sevilla: Imprenta de Hidalgo y Compañía, 1833.

Revilla de la José. "Biografía Española. Moratín”.Semanario Pintoresco Español, 1840. 289291.

Roca y Cornet, Joaquín, Cortejano Inarco. Juicio crítico de don Leandro Fernández de Moratín, como autor cómico. Barcelona: en la Imprenta y Librería de A. y F. Oliva, 1833.

Rodríguez Sánchez, Tomás. "Roca y Cornet, Joaquín". Catálogos de dramaturgos españoles del siglo XIX. Madrid: Fundación Universitaria Española, 1994. 500.

Ruiz Cabriada, Agustin. Bio-bibliografia del Cuerpo Facultativo de Archiveros, Bibliotecarios y Arqueólogos (1858- 1958). Madrid: Junta Técnica del Archivos, Bibliotecas y Museos. Sobre Joaquín Roca y Cornet, 1958. 832-836.

Salocín. "Al mérito cómico del autor del drama en tres actos El sí de las niñas". Diario de Barcelona, 24 de octubre de 1820.

Sempere y Guarinos, Juan. "Fernández de Moratín Leandro D". Ensayo de una biblioteca española de los mejores escritores del reinado de Carlos III. IV, Madrid: Imprenta Real, ed. facs., Madrid, Gredos, (1787), 1969. 130-134.

Silvela, Manuel. Vida de Don Leandro Fernández de Moratín, Obras póstumas de Leandro Fernández de Moratín. I. Madrid: Rivadeneyra, 1867. 1-58.

Torres Amat, Félix. "Roca y Cornet, D. Joaquín". Memorias para ayudar a formar un Diccionario Crítico de los Escritores Catalanes y dar alguna idea de la antigua y moderna literatura de Cataluña. Barcelona: Imprenta de J. Verdaguer, 1836. 547-549.

Zorrilla, José. “A Don Leandro Fernández de Moratín", El Clamor Público, 9 de julio de 1848. 